\title{
Early soft tissue response to zirconium oxide and titanium healing abutments in vivo: a study in dogs
}

Min Wang ${ }^{1 \dagger}$, Shuang Zhang ${ }^{2 \dagger}$, Longjie Chen ${ }^{3}$, Haixiao Zou ${ }^{4}$, Yining Wang ${ }^{5}$ and Haibin Xia ${ }^{* *}$ (1)

\begin{abstract}
Background: This study aimed to investigate the clinical characteristics and early soft tissue response to zirconium oxide ( $\mathrm{Zr}$ ) and titanium (Ti) healing abutments in dogs.

Methods: Eight implants (four at each hemi-mandible) were inserted after bilateral mandibular third and fourth premolars and first molar extraction in dogs. Then, two Zr and two Ti healing abutments were connected to each unilateral mandible eight weeks later. The ligation method was used to create a peri-implant mucositis model and the 24 abutments were divided into four groups: $\mathrm{Zr}$ or Ti healing abutments with ligation ( $\mathrm{ZrL}$, TiL) or non-ligation ( $\mathrm{ZrN}$, TiN). The clinical indices, peri-implant crevicular fluid (PICF), and inflammatory cytokines (TNF- $a$ and IL-1 $\beta$ ) were measured and analyzed on days 0 and 28. The dogs were then sacrificed on day 28 , soft tissues around the implants were harvested, and inflammation infiltration was tested by immunohistochemistry. Normal distribution test and two-way analysis of variance was used to analyze the data.
\end{abstract}

Results: The results showed that the clinical indices were similar for $\mathrm{Zr}$ and Ti healing abutments. There was significantly more PICF in the ZrL and TiL groups compared to in the ZrN and TiN groups. The TNF-a levels in PICF were significantly different between ZrL and ZrN groups on day 28. And the TNF-a levels in PICF were significantly higher in TiL group on day 28 than that on day 0 . However, the number of inflammatory cells was not significantly different between the groups as measured by immunohistochemistry.

Conclusions: These data indicate that soft tissue responses to Zr healing abutments with peri-implant mucositis were comparable to those of Ti healing abutments in vivo, providing a theoretical foundation for the clinical application of $\mathrm{Zr}$ abutments.

Keywords: Peri-implant crevicular fluid, Healing abutment, Ligation, Zirconium oxide, Titanium

*Correspondence: xhaibin@whu.edu.cn

${ }^{\dagger}$ Min Wang and Shuang Zhang have contributed equally to this article.

${ }^{1}$ The State Key Laboratory Breeding Base of Basic Science of Stomatology

(Hubei-MOST) \& Key Laboratory of Oral Biomedicine Ministry

of Education and Department of Oral Implantology, School \& Hospital

of Stomatology, Wuhan University, Wuhan 430079, China

Full list of author information is available at the end of the article

\section{Background}

Soft tissues serve as a protective barrier between the oral environment and the underlying peri-implant bone, and proper integration of soft tissues significantly affects the long-term success of implant-supported restorations [1-3]. Various hazards, including bacterial accumulation, overloading, and prosthetic manipulation, adversely affect the attachment of peri-implant soft tissues to abutments [2, 4, 5]. Furthermore, the biocompatibility of the transmucosal part of implants 
is crucial for ensuring a high quality of attachment between the mucosa and abutment.

Over the past few decades, titanium (Ti) has become the gold standard material for dental implants and implant abutments due to its excellent biocompatibility, mechanical strength, and corrosion resistance in complex oral environments [6-8]. However, its potential defects have also attracted the attention of dentistry. On the one hand, Ti abutments can hardly meet patients' increasing esthetic requirements for implantborne restorations, thus biomaterials with better optical properties are greatly needed. On the other hand, $\mathrm{Ti}$ can release sub-micrometer particles into the oral cavity, which can induce inflammatory cytokine secretion in vivo [9], or even cause potential hypersensitivity towards $\mathrm{Ti}$ in a limited number of patients [10]. Therefore, increasing esthetic demands have driven the fabrication of tooth-colored ceramic implant abutments [11, 12]. Recently, yttrium oxide-stabilized zirconium oxide $(\mathrm{Zr})$ has gained increasing attention for its excellent esthetic properties, mechanical properties, and ideal biocompatibility $[13,14]$. Importantly, fewer bacterial colonies have been reported on $\mathrm{Zr}$ surfaces than on Ti surfaces in vitro studies [15-17]. Furthermore, less soft tissue inflammation infiltration has been reported in response to $\mathrm{Zr}$ healing caps compared to Ti healing caps [18].

Nevertheless, an ideal implant abutment material should have the ability to maintain long-term homeostasis of the peri-implant mucosal microenvironment, there are several studies on the responses of periimplant soft tissue to abutments [1, 18-21]. However, most of these studies were conducted without inflammatory challenges. There are few studies on the responses of soft tissue to abutments in inflammatory environment. Therefore, the purpose of this study was to investigate the clinical characteristics and early soft tissue response to $\mathrm{Zr}$ and $\mathrm{Ti}$ healing abutments with or without peri-implant mucositis induced by ligation. This study fills the current gap in $\mathrm{Zr}$ abutment research (clinical evaluation in an inflammatory environment) and provides a solid theoretical foundation for its clinical application.

\section{Methods}

The study protocol was approved by the Ethics and Institutional Animal Care and Use Committees of the School and Hospital of Stomatology, Wuhan University. This study conformed to the Arrived guidelines.

\section{Animals}

This study was performed on three 1-year-old female beagle dogs weighing $12.5-15 \mathrm{~kg}$. The dogs were purchased from Hubei Anlu Dog Farm (Hubei, China) and were individually housed and maintained on a commercial diet and water ad libitum. Their health was checked and maintained daily.

\section{Implant design and surfaces}

A total of 24 implants with a cylinder design, $8.0-\mathrm{mm}$ length, and $3.5-\mathrm{mm}$ diameter were fabricated from grade 2 unalloyed Ti rods. An inner threaded hole was made to fit the $\mathrm{Zr}$ and $\mathrm{Ti}$ healing abutments, and the implants were then ultrasonically washed first in acetone, then in ethanol, and finally in deionized water; this process was repeated three times. The surfaces were sandblasted and acid-etched as previously described [22].

\section{Surgery procedures}

The experimental schedule is shown in Fig. 1. All surgical procedures were performed under general anesthesia using intravenous sodium pentobarbital $(3 \%, 1 \mathrm{~mL} / \mathrm{kg}$; Merck, Germany). Local instillation with 1-2-ml Primacaine adrenaline (Acteon, France) was administered for hemostasis and to reduce postoperative pain. Streptomycin and penicillin were administered postoperatively for four days.

After two weeks of adaptive feeding, the mandibular third and fourth premolars and first molar (P3-M1) were bilaterally extracted. After eight weeks [23], a fullthickness mucoperiosteal flap was evaluated, and eight implants, four at each hemi-mandible, were inserted in each dog. In total, 24 implants were used across the three dogs. The implants were placed with their coronal margins at the level of the alveolar bone crest (Fig. 2a). Cover screws were installed, and the flaps were sutured.

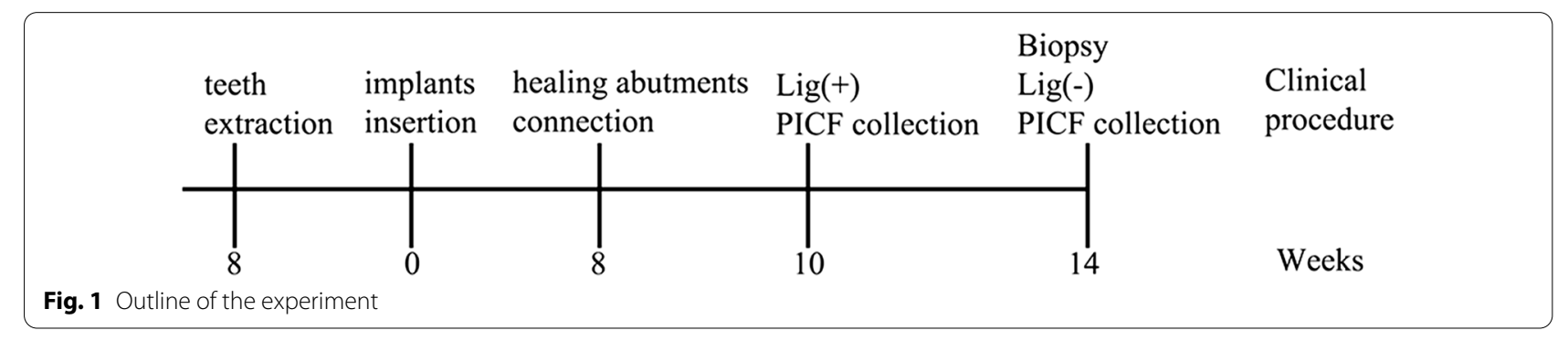



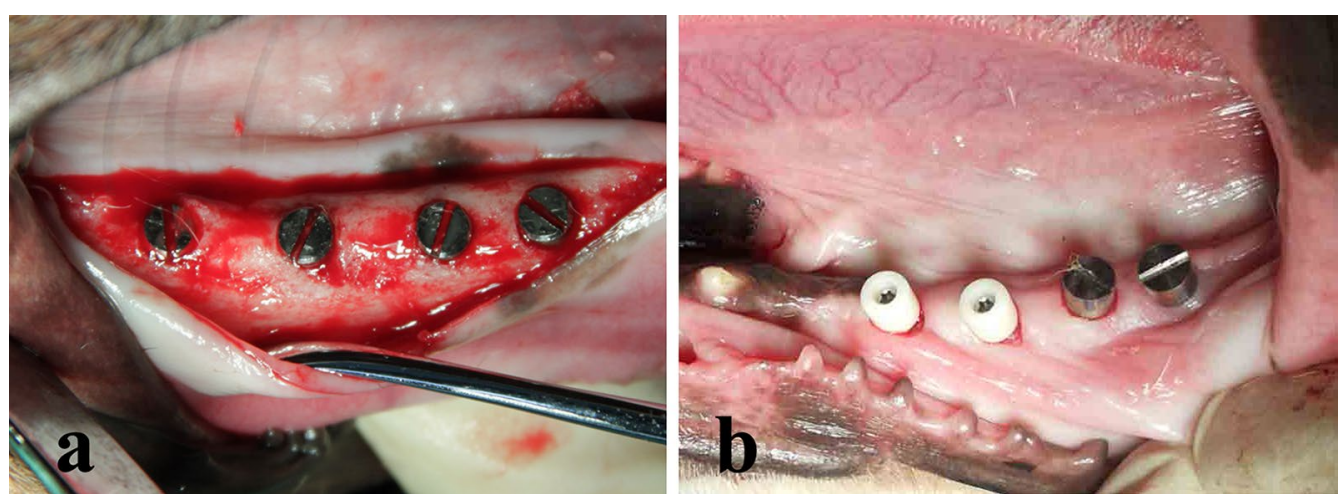

Fig. 2 a Occlusal view of the implant insertion in the unilateral mandibular edentulous region. b Occlusal view of the Zr and Ti healing abutments connection

After another eight weeks of healing, the implants were exposed using a circular scalpel. Then, two $\mathrm{Zr}$ and two Ti healing abutments were connected randomly to each unilateral mandible (Fig. 2b) and oral hygiene maintenance was initiated. After two weeks, the plaque index $(\mathrm{PI})$, gingival index $(\mathrm{GI})$, and probing depth $(\mathrm{PD})$ were recorded, and PICF was collected as baseline (day 0 ). Then, silk threads were placed at the neck of the healing abutments randomly on one side for each dog to promote plaque accumulation as the ligation groups $[24,25]$. On the contralateral side, the healing abutments were carefully cleaned using Colgate dentilave every two days as the control groups. The implants were divided into four groups: $\mathrm{Zr}$ healing abutments with ligation $(\mathrm{ZrL})(\mathrm{n}=6)$, Ti healing abutments with ligation (TiL) $(n=6)$, Zr healing abutments without ligation $(\mathrm{ZrN})(\mathrm{n}=6)$, and $\mathrm{Ti}$ healing abutments without ligation $(\mathrm{TiN})(\mathrm{n}=6)$. Then 28 days later, the PI, GI, and PD were recorded, and PICF was collected.

\section{Clinical measurements}

Clinical measurements were obtained at six sites around the healing abutments on days 0 and 28. The PI [26] and GI [27] were initially scored, followed by PICF sampling, and finally, PD was recorded. All clinical examinations were performed by one examiner.

\section{PICF sampling and processing}

Any supragingival plaque attached to healing abutments was gently cleaned using wet cotton balls. The implants were then isolated using cotton rolls and gently air-dried, and PICF was collected using $8 \times 2$-mm filter paper strips (Whatman \#3, United States). The paper strips were inserted into the mesial- and distal-buccal sulcus of the healing abutment until slight resistance was felt and then remained there for $30 \mathrm{~s}$. Any strips contaminated with bleeding or exudates were discarded. The volume of PICF was calculated by weighing and subtracting the value before and after PICF collection using a precise electronic balance. The strips were then stored at $-70{ }^{\circ} \mathrm{C}$ until further analysis.

\section{Enzyme-linked immunosorbent assay (ELISA) analysis}

The PICF samples were thawed and eluted according to the Griffiths' method [28]. Two ELISA kits (CATA00, DY3747, R\&D, USA) were used to determine the levels of TNF- $\alpha$ and IL-1 $\beta$. All procedures were performed according to the manufacturer's instructions. Absorbance at $450 \mathrm{~nm}$ was measured using an ELISA reader (BioTeK Instruments, Inc., Winooski, VT, USA). The levels of TNF- $\alpha$ and IL- $1 \beta$ were estimated using the standard assay criteria. All tests were performed in duplicates.

\section{Histopathological analysis}

The dogs were sacrificed by administering a lethal overdose of pentobarbital sodium. The hemi-mandibles were removed and fixed in 10\% buffered paraformaldehyde ( $\mathrm{pH}$ 7.2) for $48 \mathrm{~h}$. The specimens were carefully dissected into pieces and decalcified in a $10 \%$ ethylenediaminetetraacetic acid (EDTA) solution at $4{ }^{\circ} \mathrm{C}$ until a syringe needle could punch through encountering no resistance. The implants were carefully removed, and all specimens were embedded in paraffin blocks. Specimens were sectioned along their longitudinal axis at $5 \mu \mathrm{m}$ and stained with hematoxylin and eosin (HE) for histological examination. Then, the slices were observed under a conventional light microscope (Olympus BHS-313, Tokyo, Japan) at $\times 20$ magnification.

To identify the early inflammatory infiltration of soft tissues around the $\mathrm{Zr}$ and $\mathrm{Ti}$ healing abutments, immunohistochemistry using the avidin-biotin-peroxidase 
method was performed on 5- $\mu$ m-thick sections. After deparaffinization and rehydration, the sections were subjected to antigen retrieval using citrate buffer $(10 \mathrm{mM}$, $\mathrm{pH}$ 6.0, using a pressure cooker for $5 \mathrm{~min}$ at $120^{\circ} \mathrm{C}$ ) and endogenous peroxidase was blocked using $3 \% \mathrm{H}_{2} \mathrm{O}_{2}$ for $10 \mathrm{~min}$ at $37{ }^{\circ} \mathrm{C}$. Slides were preincubated with a protein block solution (2\% skim milk, $0.05 \%$ Triton X-100, and phosphate-buffered saline [PBS]) for $30 \mathrm{~min}$ at room temperature to prevent nonspecific binding. Immunostaining was performed by incubating the slides with primary monoclonal antibodies against TNF- $\alpha$ (1:50; R\&D, USA) and IL-1 1 (1:100; NOVUS, USA) in a humid chamber at $4{ }^{\circ} \mathrm{C}$ overnight. The reactions were developed using diaminobenzidine, and the immunostained sections were counterstained with hematoxylin. For the control experiments, the primary antibodies were replaced with PBS. Sections were observed under a conventional microscope (Olympus BHS-313, Tokyo, Japan) and photographed using a calibrated digital camera (Olympus

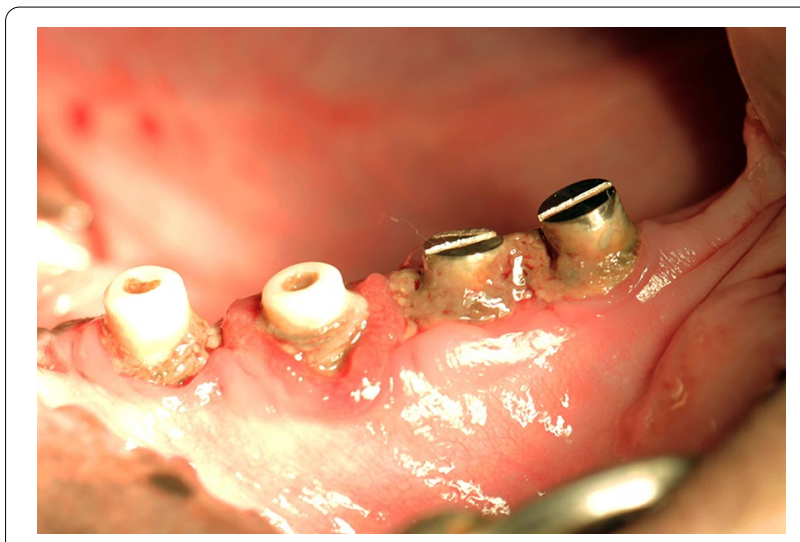

Fig. 3 The occurrence of peri-implant mucositis at day 28
C-35AD-4, Tokyo, Japan) at $\times 20$ and $\times 40$ magnification. The different markers were quantified using a specific image analysis software (Photoshop CC2019; Adobe System, San Jose, CA, USA).

\section{Statistical analysis}

Data are presented as mean \pm standard deviation (SD). Differences between the $\mathrm{Zr}$ and $\mathrm{Ti}$ implant healing abutments, with or without ligation, were evaluated using normal distribution test and two-way analysis of variance. Statistical significance was set at $p<0.05$. All statistical analyses were performed using SPSS (version 19.0; SPSS, Inc., Chicago, IL, USA).

\section{Results}

\section{Clinical findings}

Visual assessment confirmed the presence of periimplant mucositis (Fig. 3). Soft tissues around the $\mathrm{Zr}$ and Ti healing abutments were red and inflamed at the fourth week after ligation. No differences were observed in the PI and PD among the four groups on days 0 and 28 or in the GI of tissues around the $\mathrm{Zr}$ and Ti healing abutments on day 0 . However, the GI of tissues around the $\mathrm{ZrL}$ and TiL healing abutments was significantly higher than that around the $\mathrm{ZrN}$ and TiN abutments on day 28 (Table 1).

\section{Quantification of TNF- $\alpha$ and IL-1 $\beta$ in PICF}

The data was normally distributed. The volumes of PICF were similar around the $\mathrm{Zr}$ and $\mathrm{Ti}$ healing abutments on day 0 but were significantly higher in tissues around the $\mathrm{ZrL}$ and TiL abutments than in those around the $\mathrm{ZrN}$ and TiN abutments on day 28 (Table 2).

The levels of TNF- $\alpha$ and IL- $1 \beta$ in PICF around the Zr and Ti healing abutments, with or without ligation, are presented in Table 3. Although the TNF- $\alpha$ and IL-1 $\beta$

Table 1 Clinical parameters of Zr or Ti healing abutments with or without ligation

\begin{tabular}{|c|c|c|c|c|c|c|c|}
\hline & & \multicolumn{3}{|l|}{ Day 0} & \multicolumn{3}{|l|}{ Day 28} \\
\hline & & L & $\mathbf{N}$ & $P$ & $\mathrm{~L}$ & $\mathbf{N}$ & $P$ \\
\hline \multirow[t]{3}{*}{$\mathrm{Pl}$} & $\mathrm{Zr}$ & $1.2 \pm 0.98$ & $1.8 \pm 1.17$ & 0.282 & $2.3 \pm 0.52$ & $2.5 \pm 0.55$ & 0.534 \\
\hline & $\mathrm{Ti}$ & $2.2 \pm 0.98$ & $2.3 \pm 1.03$ & 0.785 & $2.7 \pm 0.52$ & $3.0 \pm 0.00$ & 0.220 \\
\hline & $P$ & 0.113 & 0.417 & & 0.220 & 0.072 & \\
\hline \multirow[t]{3}{*}{$\mathrm{Gl}$} & $\mathrm{Zr}$ & $0.3 \pm 0.5$ & $1.0 \pm 0.6$ & 0.051 & $1.5 \pm 0.6$ & $0.5 \pm 0.5$ & $0.002^{*}$ \\
\hline & $\mathrm{Ti}$ & $0.3 \pm 0.5$ & $0.5 \pm 0.5$ & 0.609 & $1.5 \pm 0.6$ & $0.8 \pm 0.4$ & $0.011^{*}$ \\
\hline & $P$ & 1.000 & 0.135 & & 1.000 & 0.431 & \\
\hline \multirow{3}{*}{$\begin{array}{l}\mathrm{PD} \\
(\mathrm{mm})\end{array}$} & $\mathrm{Zr}$ & $3.13 \pm 0.43$ & $2.92 \pm 0.38$ & 0.622 & $3.45 \pm 0.64$ & $3.08 \pm 0.66$ & 0.108 \\
\hline & $\mathrm{Ti}$ & $2.75 \pm 0.69$ & $3.58 \pm 1.20$ & 0.068 & $3.75 \pm 0.96$ & $3.3 \pm 0.63$ & 0.644 \\
\hline & $P$ & 0.386 & 0.139 & & 0.490 & 0.617 & \\
\hline
\end{tabular}

Normal distribution test and two-way analysis of variance were applied

( $P$ I plaque index, $G$ l gingival index, $P D$ probing depth, $L$ ligation, $N$ non-ligation, $P P$ value; ${ }^{*} P<0.05$ ) 
Table 2 Comparison of PICF volumes around $\mathrm{Zr}$ and Ti healing abutments with or without ligation (mg)

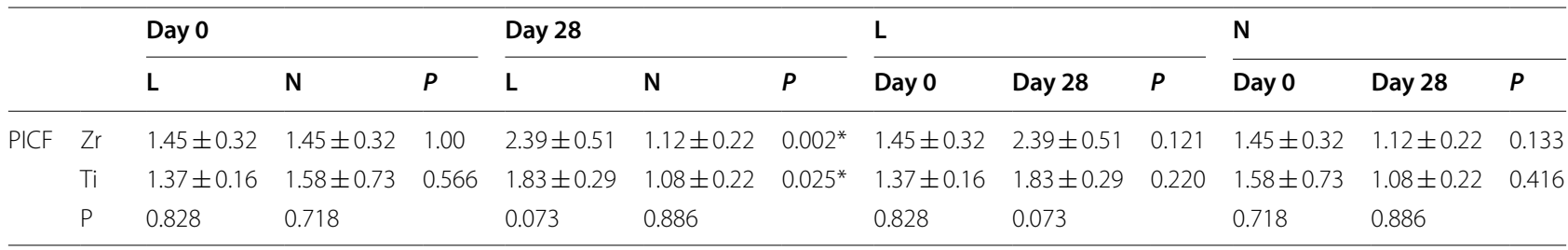

Normal distribution test and two-way analysis of variance were applied

( $L$ ligation, $N$ non-ligation, $P P$ value; ${ }^{*} P<0.05$ )

Table 3 TNF- $a$ and IL-1 $\beta$ quantification in PICF around Zr and Ti healing abutments with or without ligation (pg/ml)

\begin{tabular}{|c|c|c|c|c|c|c|c|c|c|c|c|c|c|}
\hline & & \multicolumn{3}{|l|}{ Day 0} & \multicolumn{3}{|l|}{ Day 28} & \multicolumn{3}{|l|}{$\mathrm{L}$} & \multicolumn{3}{|l|}{$N$} \\
\hline & & $\mathrm{L}$ & $\mathrm{N}$ & $P$ & L & $\mathbf{N}$ & $P$ & Day 0 & Day 28 & $P$ & Day 0 & Day 28 & $P$ \\
\hline \multirow[t]{3}{*}{ TNF-a } & $\mathrm{Zr}$ & $4.25 \pm 1.50$ & $3.66 \pm 1.40$ & 0.550 & $7.85 \pm 3.98$ & $4.09 \pm 1.64$ & $0.022^{*}$ & $4.25 \pm 1.50$ & $7.85 \pm 3.98$ & 0.127 & $3.66 \pm 1.40$ & $4.09 \pm 1.64$ & 0.725 \\
\hline & $\mathrm{Ti}$ & $3.32 \pm 1.03$ & $4.67 \pm 2.36$ & 0.468 & $6.95 \pm 2.27$ & $5.48 \pm 1.95$ & 0.343 & $3.32 \pm 1.03$ & $6.95 \pm 2.27$ & $0.011^{*}$ & $4.67 \pm 2.36$ & $5.48 \pm 1.95$ & 0.585 \\
\hline & $P$ & 0.535 & 0.482 & & 0.556 & 0.369 & & 0.535 & 0.556 & & 0.482 & 0.369 & \\
\hline \multirow[t]{3}{*}{$\mathrm{IL}-1 \beta$} & $\mathrm{Zr}$ & $1.25 \pm 0.22$ & $1.32 \pm 0.26$ & 0.642 & $1.52 \pm 0.28$ & $1.12 \pm 0.34$ & 0.393 & $1.25 \pm 0.22$ & $1.52 \pm 0.28$ & 0.538 & $1.32 \pm 0.26$ & $1.12 \pm 0.34$ & 0.525 \\
\hline & $\mathrm{Ti}$ & $1.11 \pm 0.18$ & $1.23 \pm 0.16$ & 0.426 & $1.67 \pm 0.35$ & $1.00 \pm 0.20$ & 0.173 & $1.11 \pm 0.18$ & $1.67 \pm 0.35$ & 0.396 & $1.23 \pm 0.16$ & $1.00 \pm 0.20$ & 0.429 \\
\hline & P & 0.349 & 0.542 & & 0.758 & 0.809 & & 0.349 & 0.758 & & 0.542 & 0.809 & \\
\hline
\end{tabular}

Normal distribution test and two-way analysis of variance were applied

( $L$ ligation, $N$ non-ligation, $P$ P value; ${ }^{*} P<0.05$ )

levels were similar around the $\mathrm{Zr}$ and Ti healing abutments on day 0 , they were higher around the $\mathrm{ZrL}$ and TiL abutments than around the $\mathrm{ZrN}$ and TiN abutments on day 28. However, only the levels of TNF- $\alpha$ were significantly different between the $\mathrm{ZrL}$ and $\mathrm{ZrN}$ groups on day $28(P=0.022)$. The TNF- $\alpha$ level in PICF was significantly higher in TiL group on day 28 than that on day 0 $(P=0.011)$.

\section{Histological observations and histomorphometrical measurements}

In the sections stained with $\mathrm{HE}$, the collagen fiber bundles were oriented parallel to the surfaces of the $\mathrm{ZrN}$ and TiN healing abutments. The collagen fiber bundles were denser around the $\mathrm{Zr}$ healing abutments than around the Ti healing abutments, whereas fibroblasts were fewer around the $\mathrm{Zr}$ healing abutments than around the $\mathrm{Ti}$ healing abutments. Moreover, the epithelium proximate to the TiN healing abutments was more deeply stained than that proximate to the $\mathrm{ZrN}$ healing abutments. While the early soft tissue responses to the $\mathrm{ZrN}$ and TiN healing abutments were similar. The collagen fiber bundles adjacent to the $\mathrm{ZrL}$ and TiL healing abutments were disordered, and there was a higher number of fibroblasts stained deeper in the healing abutments with ligation than in those without ligation (Fig. 4).
Immunohistochemical staining for TNF- $\alpha$ and IL-1 $\beta$ revealed the expression of positive inflammatory cells at the basement membrane zone, soft tissues adjacent to healing abutments, and endothelial cells of vessels in the vicinity (Figs. 5, 6). The inflammatory infiltrations were more obvious in tissues adjacent to the ZrL and TiL healing abutments than in those adjacent to the $\mathrm{ZrN}$ and $\mathrm{TiN}$ healing abutments. The mean amount of TNF- $\alpha$ positive inflammatory cells were $140.1 \pm 25.4$ and $160.1 \pm 30.3$ in the tissues adjacent to the $\mathrm{ZrL}$ and TiL healing abutments, respectively $(P=0.353)$, and $113.6 \pm 11.2$ and $114.8 \pm 41.8$ in those adjacent to the $\mathrm{ZrN}$ and TiN healing abutments, respectively $(P=0.963)$. Furthermore, the mean amounts of IL- $1 \beta$ positive inflammatory cells were $160.4 \pm 45.1$ and $214.9 \pm 21.0$ in the soft tissues adjacent to the $\mathrm{ZrL}$ and TiL healing abutments, respectively $(P=0.123)$, and $115.5 \pm 23.1$ and $134.6 \pm 54.7$ in those adjacent to the $\mathrm{ZrN}$ and TiN healing abutments, respectively $(P=0.563)$.

\section{Discussion}

The properties of abutment materials can significantly influence the quality of mucosal attachment formation [2]. Recently, $\mathrm{Zr}$ abutments were introduced to improve the esthetics of implantation treatment of the maxillary anterior teeth, particularly in patients with thin mucosa [29]. However, there are only limited data on the soft 


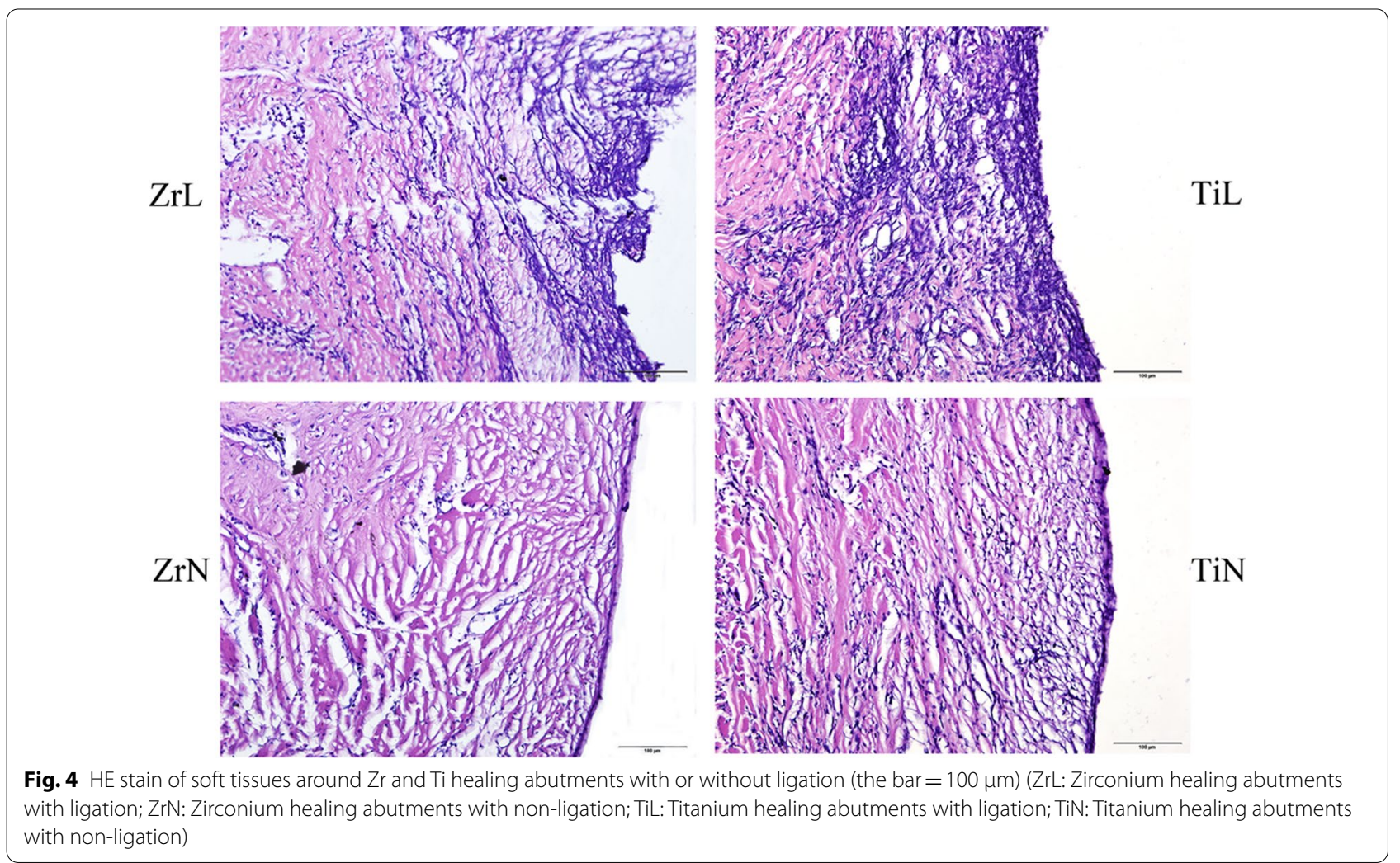

\begin{tabular}{|c|c|c|c|}
\hline $\mathrm{ZrN}$ & 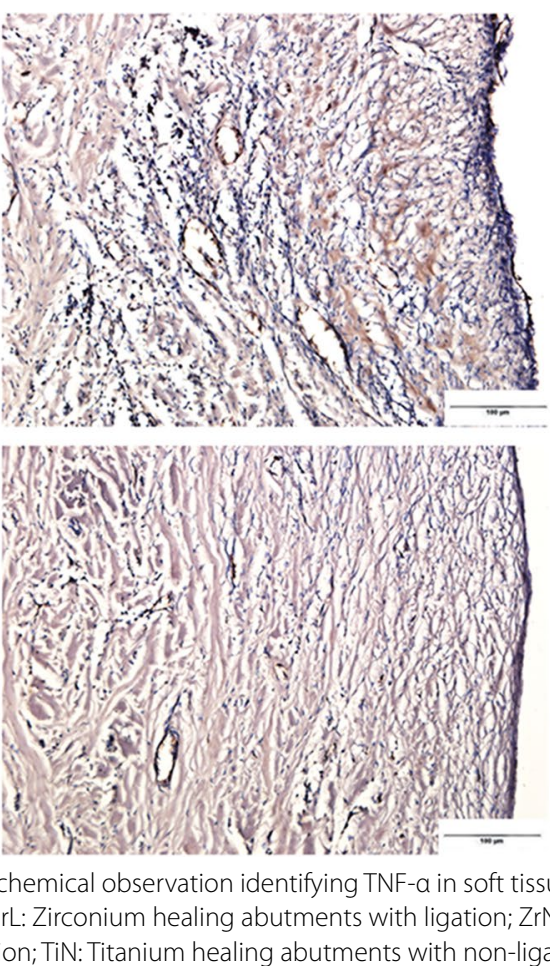 & 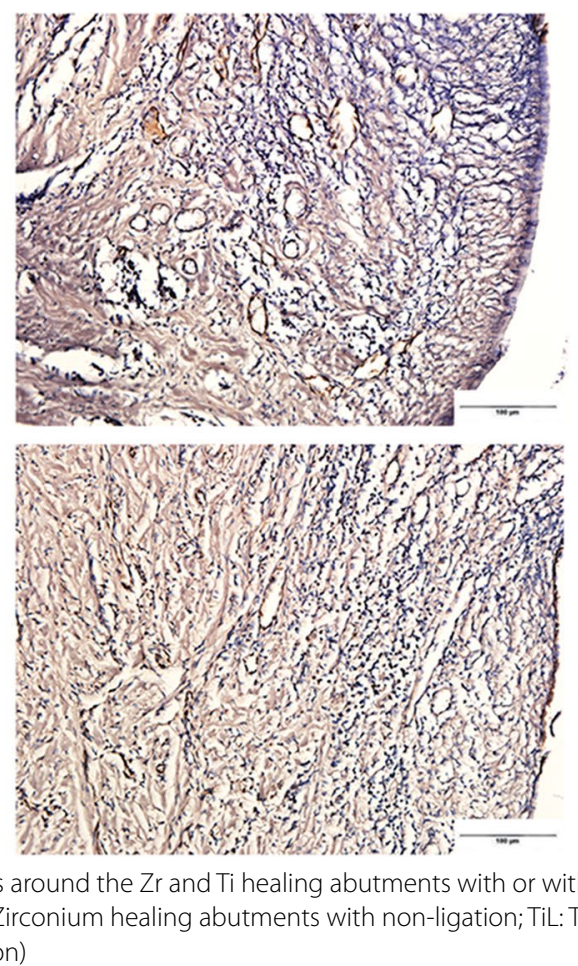 & It ligation \\
\hline
\end{tabular}




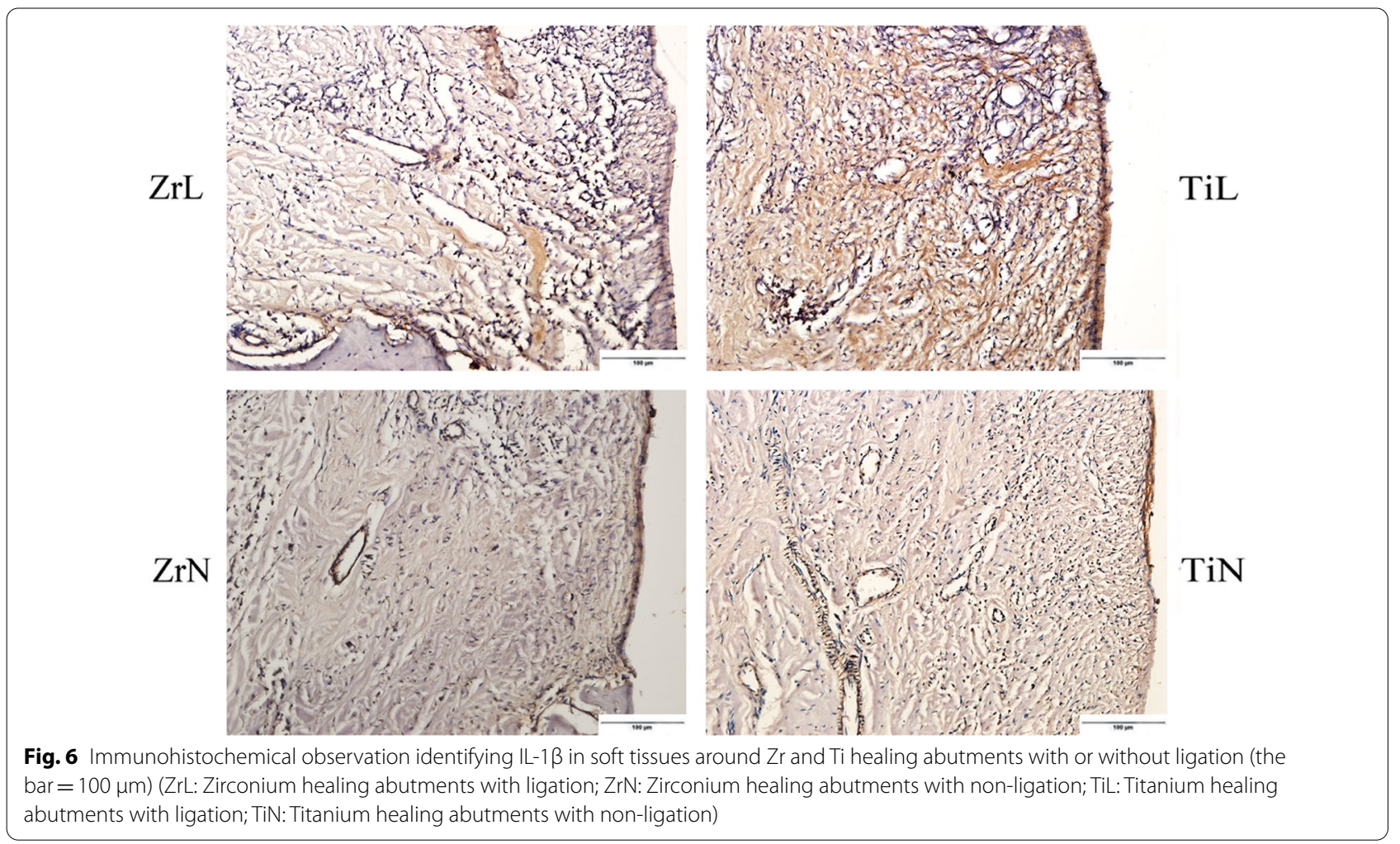

tissue response to $\mathrm{Zr}$, particularly in comparison with the response to $\mathrm{Ti}$ under peri-implantitis conditions. This within-subjects design study provides valid data comparing the expression of proinflammatory cytokines in PICF and the inflammatory infiltration of soft tissues around implant abutments fabricated from $\mathrm{Zr}$ and $\mathrm{Ti}$ with and without ligation. Importantly, we found no evidence of significant differences between the two types of biomaterials.

The results of this study demonstrates that periimplant mucosal inflammation occurs around the $\mathrm{ZrL}$ and TiL healing abutments, and that soft tissues around these abutments becomes red and swollen. Furthermore, the GI was significantly higher in specimens with the $\mathrm{ZrL}$ and TiL healing abutments than in those with the $\mathrm{ZrN}$ and TiN healing abutments on day 28 . However, no significant differences were found in PD, indicating that the type of inflammation induced by this procedure was peri-implant mucositis without bone loss. This result is consistent with that of a previous study in dogs, which indicated that peri-implant bone resorption occurred at 12 weeks after ligation [30].

We observed significantly increased volumes of PICF in the tissues around the ZrL and TiL healing abutments compared to those around the $\mathrm{ZrN}$ and TiN healing abutments on day 28 , which was related to the occurrence of peri-implant mucositis. These results are in good accordance with previous studies, demonstrating a significantly increase in the volume of PICF after plaque accumulation [31, 32]. However, after oral hygiene behaviors were resumed, the volume decreased. These findings demonstrates that oral hygiene reduces peri-implant mucosal inflammation [31]. These data suggests that an increased volume of PICF could be a useful marker of the early inflammation in peri-implant soft tissues.

Investigations of the biochemical parameters in the gingival sulcus or PICF have become increasingly popular as this allows for monitoring of the health status of the gingiva and peri-implant mucosa [31, 32]. These biochemical methods allow for early diagnosis and potential applications in disease prevention. It has been shown that the levels of TNF- $\alpha$ and IL- $1 \beta$ in PICF were positively correlated associated with peri-implant mucositis and peri-implantitis $[31,33,34]$. TNF- $\alpha$ and IL- $1 \beta$ are primarily secreted by monocytes and macrophages, and are potent multifunctional cytokines acting as proinflammatory proteins in numerous signal transduction processes during inflammation. Therefore, we analyzed the levels of TNF- $\alpha$ and IL- $1 \beta$ in PICF in addition to clinical parameters.

In this study, we observed increased levels of TNF- $\alpha$ and IL- $1 \beta$ in the PICF of tissues around the ZrL and TiL healing abutments on day 28 . However, only the levels of TNF- $\alpha$ were significantly different between the ZrL and 
ZrN groups on day 28 , and the TNF- $\alpha$ level was significantly higher in TiL group on day 28 than that on day 0 . Nevertheless, no significant differences in the levels of IL- $1 \beta$ were observed in this study. The findings of TNF- $\alpha$ and IL- $1 \beta$ in PICF obtained in the present study are in good agreement with the clinical findings, indicating that TNF- $\alpha$ could be useful markers for assessing early periimplant health status with inflammation.

In this study, no differences were observed in the soft tissue inflammatory infiltration around the $\mathrm{Zr}$ and $\mathrm{Ti}$ healing abutments. However, fewer inflammatory cells were observed around the $\mathrm{Zr}$ healing abutments than around the Ti healing abutments. Similar results were also observed in a recent study conducted by Brakel et al. [20], who reported no differences in the inflammation grading scale score in peri-implant mucosa adjacent to the $\mathrm{Zr}$ and $\mathrm{Ti}$ abutments. Consistently, previous study in canines showed that peri-implant soft tissue histomorphology compositions were similar in implant abutments made of $\mathrm{Zr}$ and $\mathrm{Ti}$ after nine months of healing [35]. In addition, one recent human histology pilot study compared inflammatory responses of different dental implant abutment materials, and the results indicated that inflammation around $\mathrm{Zr}$ and $\mathrm{Ti}$ abutments were similar [36]. On the contrary, a study in canines conducted by Welander et al. [1] reported less inflammatory infiltration in the epithelium of the peri-implant mucosa around the $\mathrm{Zr}$ abutments compared to that around the Ti abutments. In a human histological study, Degidi et al. [18] reported significant elevations in the proinflammatory infiltrates (lymphocytes, plasma cells, and histiocytes) as well as an increased expression of vascular endothelial growth factor and nitric oxide synthase isoforms 1 and 3 in the tissues adjacent to the Ti healing abutments compared to those around the $\mathrm{Zr}$ healing abutments after a 6-month healing phase. Whether this observation was attributable to the favorable attachment properties of the surrounding connective tissues and the epithelium was not conclusively established. This is because the reduction in the inflammatory reactions may not merely be an expression of better insulation through the soft tissue, but may also be related to the well-established reduction in accumulation of bacteria found on ceramic surfaces [16, 17].

The immunohistochemistry assays in our study revealed the presence of inflammatory cells at the basement membrane zone, in the soft tissues adjacent to healing abutments, and in the small endothelial cells of vessels in the vicinity. These inflammatory cells may be related to Langerhans cells in the basal layer and vascular endothelial cells. Langerhans cells are lymphocyte antigen-presenting cells that play an important role in the early immune response of periodontitis or gingivitis [37], while vascular endothelial cells are involved in inflammatory processes via the release of proinflammatory cytokines.

\section{Conclusions}

Within the limitations of this study, our findings indicate that soft tissue responses to $\mathrm{Zr}$ healing abutments with peri-implant mucositis are comparable to those to $\mathrm{Ti}$ healing abutments in vivo, providing a theoretical foundation for the clinical application of Zr.

\section{Abbreviations \\ EDTA: Ethylenediaminetetraacetic acid; ELISA: Enzyme-linked immunosorbent assay; GI: Gingival index; HE: Hematoxylin and eosin; L: Ligation; N: Non-liga- tion; PBS: Phosphate-buffered saline; PD: Probing depth; PI: Plaque index; PICF: Peri-implant crevicular fluid; SD: Standard deviation; Ti:Titanium; TiL: Ti healing abutments with ligation; TiN: Ti healing abutments without ligation; Zr: Zirco- nium oxide; ZrL: Zirconium healing abutments with ligation; ZrN: Zirconium healing abutments with non-ligation.}

\section{Acknowledgements}

We acknowledge the Nobel Biocare Company for providing all-ceramic healing abutments.

\section{Authors' contributions}

Study design: YW, HX. Animal surgeries and data analyses: MW, SZ, LC, HZ. Drafted the manuscript: MW, SZ, HX. All authors have read and approved the final manuscript.

\section{Funding}

The work was funded by the National Natural Science Foundation of China (81500866) and Lanzhou Talent Innovation and Entrepreneurship Support Project. The funders had no role in study design, data collection and analysis, decision to publish, or preparation of the manuscript.

\section{Availability of data and materials}

The data of this study are available from the corresponding author, HX, upon reasonable request.

\section{Declarations}

\section{Ethics approval and consent to participate}

All applicable international, national, and/or institutional guidelines for the care and use of animals were followed. All procedures in this study involving animals were performed in accordance with the ethical standards of the institutional and national research committee. The study protocol was approved by the Ethics and Institutional Animal Care and Use Committees of the School and Hospital of Stomatology, Wuhan University. This study conformed to the ARRIVE guidelines.

\section{Consent to publish}

Not Applicable.

\section{Competing interests}

The authors declare that they have no competing interest.

\section{Author details}

${ }^{1}$ The State Key Laboratory Breeding Base of Basic Science of Stomatology (Hubei-MOST) \& Key Laboratory of Oral Biomedicine Ministry of Education and Department of Oral Implantology, School \& Hospital of Stomatology, Wuhan University, Wuhan 430079, China. ${ }^{2}$ The State Key Laboratory Breeding Base of Basic Science of Stomatology (Hubei-MOST) and Key Laboratory of Oral Biomedicine Ministry of Education and Department of Preventive Dentistry, School and Hospital of Stomatology, Wuhan University, Wuhan 430079, China. ${ }^{3}$ Lanzhou Hospital of Stomatology, Lanzhou 730000, China. ${ }^{4}$ Department of Stomatology, Second Affiliated Hospital of Nanchang University, Nanchang University, Nanchang 330006, China. ${ }^{5}$ The State Key Laboratory 
Breeding Base of Basic Science of Stomatology (Hubei-MOST) and Key Laboratory of Oral Biomedicine Ministry of Education and Department of Prosthodontics, School and Hospital of Stomatology, Wuhan University, Wuhan 430079, China.

Received: 20 January 2021 Accepted: 19 July 2021

Published online: 24 August 2021

\section{References}

1. Welander M, Abrahamsson I, Berglundh T. The mucosal barrier at implant abutments of different materials. Clin Oral Implants Res. 2008;19(7):635-41.

2. Abrahamsson I, Berglundh T, Lindhe J. The mucosal barrier following abutment dis/reconnection. An experimental study in dogs. J Clin Periodontol. 1997:4(8):568-72.

3. Lindhe J, Berglundh T. The interface between the mucosa and the implant. Periodontol. 2000;1998(17):47-54.

4. Barboza EP, Caula AL, Carvalho WR. Crestal bone loss around submerged and exposed unloaded dental implants: a radiographic and microbiological descriptive study. Implant Dent. 2002;11(2):162-9.

5. Misch CE, Dietsh-Misch F, Hoar J, Beck G, Hazen R, Misch CM. A bone quality-based implant system: first year of prosthetic loading. J Oral Implantol. 1999;25(3):185-97.

6. Linkevicius T, Apse P. Influence of abutment material on stability of peri-implant tissues: a systematic review. Int J Oral Maxillofac Implants. 2008;23(3):449-56.

7. Lekholm U, Gunne J, Henry P, Higuchi K, Linden U, Bergstrom C, et al. Survival of the Branemark implant in partially edentulous jaws: a 10-year prospective multicenter study. Int J Oral Maxillofac Implants. 1999;14(5):639-45.

8. Ekelund JA, Lindquist LW, Carlsson GE, Jemt T. Implant treatment in the edentulous mandible: a prospective study on Branemark system implants over more than 20 years. Int J Prosthodont. 2003;16(6):602-8.

9. Taira M, Kagiya T, Harada H, Sasaki M, Kimura S, Narushima T, et al. Microscopic observations and inflammatory cytokine productions of human macrophage phagocytising submicron titanium particles. J Mater Sci Mater Med. 2010;21(1):267-75.

10. Siddiqi A, Payne A, De Silva R, Duncan W. Titanium allergy: could it affect dental implant integration? Clin Oral Implants Res. 2011;22(7):673-80.

11. Prestipino V, Ingber A. Esthetic high-strength implant abutments. Part II. J Esthet Dent. 1993;5(2):63-8.

12. Prestipino V, Ingber A. Esthetic high-strength implant abutments. Part I. J Esthet Dent. 1993;5(1):29-36.

13. Holst S, Blatz MB, Hegenbarth E, Wichmann M, Eitner S. Prosthodontic considerations for predictable single-implant esthetics in the anterior maxilla. J Oral Maxillofac Surg. 2005;63(9 Suppl 2):89-96.

14. Denry I, Kelly JR. State of the art of zirconia for dental applications. Dent Mater. 2008;24(3):299-307.

15. van Brakel R, Cune MS, van Winkelhoff AJ, de Putter C, Verhoeven JW, van der Reijden W. Early bacterial colonization and soft tissue health around zirconia and titanium abutments: an in vivo study in man. Clin Oral Implants Res. 2011;22(6):571-7.

16. Scarano A, Piattelli M, Caputi S, Favero GA, Piattelli A. Bacterial adhesion on commercially pure titanium and zirconium oxide disks: an in vivo human study. J Periodontol. 2004;75(2):292-6.

17. Rimondini L, Cerroni L, Carrassi A, Torricelli P. Bacterial colonization of zirconia ceramic surfaces: an in vitro and in vivo study. Int J Oral Maxillofac Implants. 2002;17(6):793-8.

18. Degidi M, Artese L, Scarano A, Perrotti V, Gehrke P, Piattelli A. Inflammatory infiltrate, microvessel density, nitric oxide synthase expression, vascular endothelial growth factor expression, and proliferative activity in peri-implant soft tissues around titanium and zirconium oxide healing caps. J Periodontol. 2006;77(1):73-80.

19. Tete S, Mastrangelo F, Bianchi A, Zizzari V, Scarano A. Collagen fiber orientation around machined titanium and zirconia dental implant necks: an animal study. Int J Oral Maxillofac Implants. 2009;24(1):52-8.
20. van Brakel R, Meijer GJ, Verhoeven JW, Jansen J, de Putter C, Cune MS. Soft tissue response to zirconia and titanium implant abutments: an in vivo within-subject comparison. J Clin Periodontol. 2012;39(10):995-1001.

21. Barwacz CA, Brogden KA, Stanford CM, Dawson DV, Recker EN, Blanchette D. Comparison of pro-inflammatory cytokines and bone metabolism mediators around titanium and zirconia dental implant abutments following a minimum of 6 months of clinical function. Clin Oral Implants Res. 2015;26(4):e35-41.

22. Zhou Y, Jiang T, Qian M, Zhang X, Wang J, Shi B, et al. Roles of bone scintigraphy and resonance frequency analysis in evaluating osseointegration of endosseous implant. Biomaterials. 2008;29(4):461-74.

23. Orsini E, Salgarello S, Bubalo M, Lazic Z, Trire A, Martini D, et al. Histomorphometric evaluation of implant design as a key factor in peri-implant bone response: a preliminary study in a dog model. Minerva Stomatol. 2009;58(6):263-75.

24. Shibli JA, Martins MC, Lotufo RF, Marcantonio E. Microbiologic and radiographic analysis of ligature-induced peri-implantitis with different dental implant surfaces. Int J Oral Maxillofac Implants. 2003;18(3):383-90.

25. Lang NP, Bragger U, Walther D, Beamer B, Kornman KS. Ligature-induced peri-implant infection in cynomolgus monkeys. I. Clinical and radiographic findings. Clin Oral Implants Res. 1993;4(1):2-11.

26. Loe $H$, Theilade $E$, Jensen SB. Experimental gingivitis in man. J Periodontol. 1965;36:177-87.

27. Loe H. The Gingival Index, the Plaque Index and the Retention Index Systems. J Periodontol. 1967;38(6):610-6.

28. Griffiths GS, Curtis MA, Wilton JM. Selection of a filter paper with optimum properties for the collection of gingival crevicular fluid. J Periodontal Res. 1988;23(1):33-8.

29. Jung RE, Holderegger C, Sailer I, Khraisat A, Suter A, Hammerle CH. The effect of all-ceramic and porcelain-fused-to-metal restorations on marginal peri-implant soft tissue color: a randomized controlled clinical trial. Int J Periodontics Restor Dent. 2008;28(4):357-65.

30. Albouy JP, Abrahamsson I, Persson LG, Berglundh T. Spontaneous progression of peri-implantitis at different types of implants. An experimental study in dogs. I: clinical and radiographic observations. Clin Oral Implants Res. 2008;19(10):997-1002.

31. Schierano G, Pejrone G, Brusco P, Trombetta A, Martinasso G, Preti G, et al. TNF-alpha TGF-beta2 and IL-1 beta levels in gingival and peri-implant crevicular fluid before and after de novo plaque accumulation. J Clin Periodontol. 2008;35(6):532-8.

32. Petkovic AB, Matic SM, Stamatovic NV, Vojvodic DV, Todorovic TM, Lazic $\mathrm{ZR}$, et al. Proinflammatory cytokines (IL-1 beta and TNF-alpha) and chemokines (IL-8 and MIP-1alpha) as markers of peri-implant tissue condition. Int J Oral Maxillofac Surg. 2010;39(5):478-85.

33. Panagakos FS, Aboyoussef H, Dondero R, Jandinski JJ. Detection and measurement of inflammatory cytokines in implant crevicular fluid: a pilot study. Int J Oral Maxillofac Implants. 1996;11 (6):794-9.

34. Ataoglu H, Alptekin NO, Haliloglu S, Gursel M, Ataoglu T, Serpek B, et al. Interleukin-1 beta, tumor necrosis factor-alpha levels and neutrophil elastase activity in peri-implant crevicular fluid. Clin Oral Implants Res. 2002;13(5):470-6.

35. Blanco J, Caneiro L, Linares A, Batalla P, Munoz F, Ramos I. Peri-implant soft tissue analyses comparing Ti and ZrO2 abutments: an animal study on beagle dogs. Clin Oral Implants Res. 2016;27(10):1221-6.

36. Sampatanukul T, Serichetaphongse P, Pimkhaokham A. Histological evaluations and inflammatory responses of different dental implant abutment materials: a human histology pilot study. Clin Implant Dent Relat Res. 2018;20(2):160-9.

37. Cury PR, Furuse C, Rodrigues AE, Barbuto JA, Araujo VC, Araujo NS. Interstitial and Langerhans' dendritic cells in chronic periodontitis and gingivitis. Braz Oral Res. 2008;22(3):258-63.

\section{Publisher's Note}

Springer Nature remains neutral with regard to jurisdictional claims in published maps and institutional affiliations. 